\title{
Effect of sub-lethal chemical disinfection on the biofilm forming ability, resistance to antibiotics and expression of virulence genes of Salmonella Enteritidis biofilm-surviving cells
}

\author{
Maria João Romeu (D), Diana Rodrigues and Joana Azeredo \\ Laboratório de Investigação em Biofilmes Rosário Oliveira, Centre of Biological Engineering, University of Minho, Braga, Portugal
}

\begin{abstract}
Although disinfection procedures are widely implemented in food environments, bacteria can survive and present increased virulence/resistance. Since little is known about these phenomena regarding biofilms, this study aimed to investigate the effect of chemical disinfection on biofilmderived cells of Salmonella Enteritidis. Using a reference strain (NCTC 13349) and a food isolate (350), biofilm susceptibility to benzalkonium chloride (BAC), sodium hypochlorite (SH) and hydrogen peroxide (HP) was evaluated and biofilms were exposed to sub-lethal concentrations of each disinfectant. Biofilm-derived cells were characterized for their biofilm forming ability, antibiotic resistance and expression of virulence-associated genes. Except for a few instances, disinfectant exposure did not alter antibiotic susceptibility. However, SH and HP exposure enhanced the biofilm forming ability of Salmonella Enteritidis NCTC 13349. After BAC and HP exposure, biofilm-derived cells presented a down-regulation of rpoS. Exposure to $B A C$ also revealed an up-regulation of invA, avrA and $\operatorname{csg} D$ on Salmonella Enteritidis NCTC 13349. The results obtained suggest that biofilm-derived cells that survive disinfection may represent an increased health risk.

Abbreviations: AMP: Ampicillin; BAC: Benzalkonium chloride; cDNA: Complementary deoxyribonucleic acid; CEF: Cefotaxime; CFUs: Colony Forming Units; CIP: Ciprofloxacin; CLO: Chloramphenicol; CV: Crystal violet; DNA: Deoxyribonucleic acid; HP: Hydrogen peroxide; LB: Luria Bertani Broth Miller; LBA: Luria Broth Agar; MBEC: Minimum Biofilm Eradication Concentration; MIC: Minimum Inhibitory Concentration; NRT: No Reverse Transcriptase control; NTC: No Template Control; OD: Optical density; RNA: Ribonucleic acid; rRNA: Ribosomal ribonucleic acid; SH: Sodium hypochlorite; TET: Tetracycline
\end{abstract}

ARTICLE HISTORY

Received 10 October 2019

Accepted 16 January 2020

\section{KEYWORDS}

Foodborne pathogens;

cross-resistance; Salmonella

Enteritidis; chemical

disinfectants; bio-

film; virulence

\section{Introduction}

Microbial contamination is an ongoing food safety concern, which has a great impact in public health and causes economic loss (Carrasco et al. 2012). Many reported foodborne outbreaks have been caused by Salmonella, with many of these being due to Salmonella Enteritidis (S. Enteritidis) the most common serotype associated with human cases (EFSA and ECDC (European Food Safety Authority and European Centre for Disease Prevention and Control) 2018). This bacterium causes a foodborne infection, salmonellosis, which is a self-limiting disease that does not usually require antibiotic therapy. However, in the most severe salmonellosis cases the main choices for antibiotic therapy are fluoroquinolones, third generation cephalosporins and ampicillin (Kit et al. 2011).
The persistence of bacteria in food processing areas is often associated with their biofilm forming ability. Indeed, Salmonella biofilms are a major problem for the food industry in food processing areas, owing to the ability of Salmonella to colonize all sorts of abiotic food contact surfaces (Giaouris et al. 2012; Steenackers et al. 2012). Moreover, cells can detach from these biofilms and quickly spread contamination through the processing line, causing cross-contamination (Moore et al. 2007). Despite sanitation procedures, pathogens may prevail due to specific characteristics of the biofilm lifestyle, which makes the bacteria more tolerant to several antimicrobial agents (Corcoran et al. 2014; Giaouris et al. 2012; Papavasileiou et al. 2010). Thus, despite the diversity of disinfectants available, previous studies have shown that bacteria can survive treatments, which can also be related with an increased resistance to antibiotics 
in a "cross-resistance" phenomenon (Condell et al. 2012). Therefore, it is important to study the mechanisms that are involved in resistance, concerning both disinfectants and antibiotics. Moreover, this subject deserves particular attention due to the possibility that resistance to disinfectants may be related to additional virulence profiles, such as alterations in the expression of virulence genes (Giaouris et al. 2013; Rodrigues et al. 2011; Wang et al. 2010). However, little is known about these phenomena concerning biofilms, which is alarming due to the increased resistance to disinfectants of cells within biofilms (Papavasileiou et al. 2010; Corcoran et al. 2014). Furthermore, the up-regulation of virulence genes in biofilm-surviving cells that have been treated with disinfectants is a subject that deserves special attention, because surviving cells may compromise food safety and potentiate the public health risk (Rodrigues et al. 2011). Additionally, the screening of different gene expression profiles caused by disinfection will help to elucidate the possible role of antimicrobial resistance mechanisms in virulence.

In this context, the purpose of the present work was to characterize $S$. Enteritidis biofilm-derived cells from two different strains after exposure to chemical disinfectants, with regard to their susceptibility to antibiotics, biofilm forming ability, and virulence gene expression, in order to infer what may occur if these cells are released from biofilms and come into contact with a host or a surface.

\section{Materials and methods}

\section{Bacterial strains and culture conditions}

To evaluate the behavior of different strains from distinct sources, two $S$. Enteritidis strains were used (one food isolate - 350; and one reference strain - NCTC 13349). Bacteria were preserved at $-70^{\circ} \mathrm{C}$ in stocks of culture media with $20 \%$ glycerol, and for each experiment strains were sub-cultured on Luria Broth Agar plates (LBA; Liofilchem) for $24 \mathrm{~h}$, at $37^{\circ} \mathrm{C}$. Bacterial suspensions were prepared by inoculation into Luria Bertani Broth Miller (LB; Liofilchem) for $18 \mathrm{~h}$ at $37^{\circ} \mathrm{C}$ in a shaker $(120 \mathrm{rpm})$ incubator (NB-205Q, N-Biotek). Cells were harvested by centrifugation at $9,000 \mathrm{rpm}$, for $5 \mathrm{~min}$ at $4{ }^{\circ} \mathrm{C}$ (5430 R Centrifuge, Eppendorf), and washed twice with $0.9 \%$ sodium chloride sterile solution (saline solution; Panreac Química). Subsequently, cell numbers were adjusted to $\approx 1 \times 10^{8} \mathrm{CFU} \mathrm{ml}{ }^{-1}$, corresponding to an optical density (OD) of $\approx 0.1$ at $640 \mathrm{~nm}$, as confirmed by colony forming unit (CFU) counts after plating on LBA. This bacterial suspension served as the inoculum for subsequent assays.

\section{Biofilm formation}

Biofilm formation was assessed using microtiter plates under optimized conditions, and each assay was performed in triplicate. Briefly, in each well of a 96-well flat-bottom polystyrene microtiter plate (Orange Scientific) a bacterial inoculum was added to LB medium to obtain a $1 \times 10^{5} \mathrm{CFU} \mathrm{ml}{ }^{-1}$ concentration in a final volume of $200 \mu \mathrm{l}$ per well. Culture plates were incubated at $37^{\circ} \mathrm{C}$ with shaking $(120 \mathrm{rpm})$ for three days, with medium renewal every $24 \mathrm{~h}$.

\section{Biofilm susceptibility to disinfectants}

\section{Disinfectants and neutralizer preparation}

Three disinfectants were tested: sodium hypochlorite (SH) $10-15 \%$ available chlorine (Sigma-Aldrich), hydrogen peroxide (HP) $50 \% \mathrm{wt} / \mathrm{v}$ solution in water (Sigma-Aldrich), and benzalkonium chloride (BAC) (Sigma-Aldrich). Disinfectant working solutions were always prepared fresh before each application. After exposure of the biofilms to the disinfectants the disinfectants were inactivated by a universal neutralizer composed of $0.05 \%$ L-histidine (SigmaAldrich), $0.05 \%$ L-cysteine (Sigma-Aldrich), and $0.1 \%$ reduced glutathione (Sigma-Aldrich). This solution was prepared in ultrapure water, sterilized by filtration and preserved at $-20^{\circ} \mathrm{C}$ (Carson et al., 2009). A fresh solution was prepared for each use, with a ratio of 1 volume of neutralizer to 40 volumes of LB.

\section{Minimum biofilm eradication concentration assay (MBEC)}

Biofilm susceptibility to disinfectants was evaluated by determining the MBEC) (Ceri et al. 1999). Briefly, three day-old biofilms were washed with saline solution to remove free cells. Thereafter, different concentrations of disinfectants were prepared in LB and added to the biofilms. After an overnight incubation $(18 \mathrm{~h})$ at $37^{\circ} \mathrm{C}$ with shaking $(120 \mathrm{rpm})$, the culture medium was discarded, biofilms were washed with saline solution and submerged in $\mathrm{LB}+$ neutralizer solution for $5 \mathrm{~min}$. Biofilms were then scraped from the wells with the aid of sterile micro spatula, plated onto LBA and incubated for $24 \mathrm{~h}$ at $37^{\circ} \mathrm{C}$. Determination of MBECs was based on CFUs enumeration, and corresponded to the disinfectant concentration that lead to the complete eradication of the biofilm (no surviving cells). 
Prolonged exposure of biofilms to Sub-lethal chemical disinfection

To assess the effect of exposure of biofilms to sublethal chemical disinfection, biofilms were formed as described above but using 24-well polystyrene plates (Orange Scientific), in order to obtain a larger amount of biomass, and incubated for 6 additional days (a total of 9-days incubation). In these six additional days, disinfection agents at half MBEC were applied on the first, second, fourth and sixth day, while on the third and fifth day only LB medium was added to the wells to study what may happen in the food industry when insufficient sanitation takes place. For the $S$. Enteritidis NCTC 13349 strain, a final concentration of $0.04,0.44$ and $0.3 \%$ for BAC, HP and $\mathrm{SH}$ respectively, and for the food isolate $S$. Enteritidis 350 strain, a final concentration of 0.4 and $0.06 \%$ for $\mathrm{HP}$ and $\mathrm{SH}$ was applied on the disinfection challenge days. In the specific case of $S$. Enteritidis 350 exposed to BAC, it was necessary to apply a concentration lower than half MBEC $(0.04 \%)$ because the number of cells that survived prolonged exposure was not sufficient to perform subsequent assays $(<5 \quad \log )$. Simultaneously, identical assays were performed without exposure to disinfectants (controls). After incubation for 9 days, biofilms were washed with saline solution, and a solution comprising LB, neutralizer, and Tween 1\% (Fisher Scientific International, US) was applied to neutralize the disinfectants and to help disrupt the biofilms. To ensure a more effective biofilm removal and cell dispersion, culture plates were placed in an ultrasonic bath (Sonicor model SC-52, UK) operating at $50,000 \mathrm{~Hz}$, for $10 \mathrm{~min}$, and then biofilms were scraped with a sterile micro spatula. Biofilm cells were harvested by centrifugation at $9,000 \mathrm{rpm} \quad(5430 \mathrm{R}$ Centrifuge, Eppendorf), $10 \mathrm{~min}, 4^{\circ} \mathrm{C}$, and resuspended in $5 \mathrm{ml}$ of saline solution. Serial dilutions of the bacterial suspensions obtained were plated onto LBA, to confirm cell concentration by CFU enumeration. Samples to be used in quantitative Real-Time Polymerase Chain Reaction (qPCR) assays were collected, immediately resuspended in $500 \mu$ l of RNAlater ${ }^{\circledR}$ solution (SigmaAldrich), and stored at $-70^{\circ} \mathrm{C}$. All these experiments were performed in triplicate, in at least three independent assays.

The possible antimicrobial effect of the solution comprising LB, neutralizer and Tween had been previously tested as follows: the biofilms were submerged in that solution and then sonicated, finally, a sample of the suspension was plated out in order to compare the number of viable biofilm cells with the controls (viable cells from biofilms not subjected to the neutralizer action). A significant reduction in bacterial numbers was not observed (data not shown).

\section{Evaluation of antibiotic susceptibility}

The antibiotic susceptibility of biofilm-derived cells exposed to disinfectants and from controls was assessed by determining their Minimum Inhibitory Concentration (MIC) (Jorgensen and Ferraro 2009). To compare the susceptibility of different lifestyles, MIC was also determined using planktonic cells not subjected to a disinfection challenge. Different antibiotics were tested: ampicillin (AMP; Sigma-Aldrich), ciprofloxacin (CIP; Sigma-Aldrich), cefotaxime (CEF; Aplichem, Germany), chloramphenicol (CLO; SigmaAldrich), and tetracycline (TET; Sigma-Aldrich). All antibiotic stock solutions were prepared at a concentration of $0.512 \%$, sterilized by filtration and stored at $-70^{\circ} \mathrm{C}$. MIC values were determined by microdilution, using flat-bottom polystyrene microtiter plates, according to EUCAST (EUCAST - The European Committee on Antimicrobial Susceptibility Testing 2019a). Briefly, all bacterial suspensions were adjusted to $1 \times 10^{5} \mathrm{CFU} \mathrm{ml}{ }^{-1}$ in each well. Microtiter plates were incubated at $37^{\circ} \mathrm{C}, 120 \mathrm{rpm}$, for $24 \mathrm{~h}$. MIC was determined visually and confirmed by OD reading at $640 \mathrm{~nm}$. All experiments were performed in triplicate, in at least three independent assays.

\section{Evaluation of biofilm formation ability}

Biofilm forming ability was evaluated by crystal violet (CV) staining (Agarwal et al. 2011). Cells from biofilms exposed or not-exposed to disinfectants were allowed to form biofilms on flat-bottom polystyrene microtiter plates, as described above. After 3 days, medium was removed and biofilms washed with saline solution to remove unattached cells. To fix the biofilms, absolute methanol was added to each well for $15 \mathrm{~min}$. Afterwards, culture plates were allowed to dry at room temperature and biofilms were then stained with $1 \% \mathrm{CV}$ solution for $5 \mathrm{~min}$, washed with saline solution to remove the excess of $\mathrm{CV}$ solution and left to dry. Finally, to solubilize the CV bound to the biofilm, 33\% acetic acid was added, and the OD was measured at $570 \mathrm{~nm}$ (Sunrise ${ }^{\mathrm{TM}}$, Tecan). All experiments were performed in triplicate, for at least three independent assays.

\section{Genetic expression analysis}

Genetic expression analysis on both biofilm cells either exposed or not-exposed to disinfectants was 
Table 1. Genes and primers used for the assessment of gene expression analysis by qPCR.

\begin{tabular}{|c|c|c|c|}
\hline Gene & Function & Sequence $\left(5^{\prime}-3^{\prime}\right)$ & Product size (bp) \\
\hline $16 S$ rRNA & $\begin{array}{l}\text { Component of the } 30 \mathrm{~S} \text { small subunit of } \\
\text { ribosome (reference gene) }\end{array}$ & $\begin{array}{l}\text { F: CAGAAGAAGCACCGGCTAAC R: } \\
\text { GACTCAAGCCTGCCAGTTTC }\end{array}$ & 167 \\
\hline avrA & $\begin{array}{l}\text { Cellular invasion and inflammatory response } \\
\text { of hosts against infection }\end{array}$ & $\begin{array}{l}\text { F: GAGCTGCTTTGGTCCTCAAC R: } \\
\text { AATGGAAGGCGTTGAATCTG }\end{array}$ & 173 \\
\hline $\operatorname{inv} A$ & Cellular invasion & $\begin{array}{l}\text { F: ATCGAGATCGCCAATCAGTC R: } \\
\text { CGCTGCCGGTATTTGTTATT }\end{array}$ & 167 \\
\hline rpos & Starvation survival & $\begin{array}{l}\text { F: GAATCTGACGAACACGCTCA R: } \\
\text { CCACGCAAGATGACGATATG }\end{array}$ & 171 \\
\hline $\operatorname{csg} D$ & $\begin{array}{l}\text { Initial adhesion and biofilm formation - } \\
\text { biosynthesis of major extracellular } \\
\text { matrix components }\end{array}$ & $\begin{array}{l}\text { F: GCCTCATATTAACGGCGTGT R: } \\
\text { TCGCGATGAGTGAGTAATGC }\end{array}$ & 177 \\
\hline
\end{tabular}

performed by the quantitative Real-Time Polymerase Chain Reaction (qPCR).

\section{Selected genes}

The genes selected were either involved in $S$. Enteritidis virulence, pathogenicity or stress-response. The genes selected were the stress-response gene rpoS, (O'Neal et al. 1994) and the virulence genes $\operatorname{csg} D$ (Latasa et al. 2005), avrA (Ben-Barak et al. 2006) and invA (Galán et al. 1992). The reference gene used was $16 S$ rRNA (ribosomal ribonucleic acid). Primers used for gene expression analysis were designed using software Primer 3 (Rozen and Skaletsky 2000). The specific functions of these genes and their primers sequences are presented in Table 1. Primer specificity and effectiveness had previously been tested (data not shown). Two negative controls, a No Reverse Transcriptase control (NRT) and a No Template Control (NTC) were included to validate the reactions.

\section{RNA (ribonucleic acid) extraction}

Total RNA was extracted using PureLink ${ }^{\mathrm{TM}}$ RNA Mini Kit (Invitrogen), and RNA purification was performed by On-column PureLink ${ }^{\mathrm{TM}}$ DNase treatment (Invitrogen), both according to manufacturer's protocols. Purified RNA was analyzed regarding concentration (ng $\mu \mathrm{l}^{-1}$ ) and purity (absorbance ratios A260/ A280 and A260/A230) using a NanoDrop device (NanoDrop 1000 Spectrophotometer, V3.6.0, Thermo Fisher Scientific, Inc.).

\section{CDNA (complementary deoxyribonucleic acid) synthesis}

To ensure equivalent starting amounts of RNA were available to be converted to cDNA and hence providing a reliable comparison of gene expression between different samples, dilutions were performed in RNase-free water. RNA concentrations were adjusted to match the least concentrated sample value. A minimum concentration of RNA template of $12 \mathrm{ng}$ $\mu \mathrm{l}^{-1}$ was required to proceed with cDNA synthesis.
cDNA synthesis was performed using iScript ${ }^{\mathrm{TM}} \mathrm{cDNA}$ Synthesis Kit (Bio-Rad). A final reaction volume of $20 \mu \mathrm{l}$ contained $4 \mu \mathrm{l}$ of $5 x i S c r i p t$ Reaction Mix, $1 \mu \mathrm{l}$ of iScript Reverse Transcriptase, and $15 \mu \mathrm{l}$ of RNA template, according to the recommended proportions. The complete reaction mix was incubated in a thermocycler (MyCycler ${ }^{\mathrm{TM}}$ Thermal Cycler, Bio-Rad) with a specific reaction protocol: $5 \mathrm{~min}$ at $25^{\circ} \mathrm{C}$, $30 \mathrm{~min}$ at $42^{\circ} \mathrm{C}$ and $5 \mathrm{~min}$ at $85^{\circ} \mathrm{C}$.

\section{$q P C R$}

qPCR was performed on a CFX96 ${ }^{\mathrm{TM}}$ Real-Time PCR Detection System Bio-Rad system (Bio-Rad Laboratories, Inc.), and each sample was run in triplicate. Standardization of cDNA concentration for each qPCR run was performed based on the adjustment of RNA concentration prior to cDNA synthesis, as explained in the section on $c D N A$. Moreover, to avoid oversampling that impairs $\mathrm{qPCR}$, prior to a $\mathrm{qPCR}$ run each cDNA sample was diluted 1:20. Primer concentrations were prepared according to the manufacturer's indications and then diluted 1:10. A total of $20 \mu \mathrm{l}$ of reaction mixture contained $2 \mu \mathrm{l}$ of diluted cDNA, $1 \mu \mathrm{l}$ of each primer $(10 \mu \mathrm{M}), 10 \mu \mathrm{l}$ of $2 \times$ SSoFast ${ }^{\mathrm{TM}} \quad$ EvaGreen $^{\circledR} \quad$ Supermix $\quad$ (Bio-Rad Laboratories, Inc.), and $6 \mu \mathrm{l}$ of nuclease-free water. Optimized thermal cycling conditions were performed: $3 \mathrm{~min}$ of initial denaturation at $95^{\circ} \mathrm{C}$, followed by 40 cycles of $10 \mathrm{~s}$ denaturation at $95^{\circ} \mathrm{C}, 10 \mathrm{~s}$ annealing at $57^{\circ} \mathrm{C}$ (concerning primers efficiency previously determined), and $15 \mathrm{~s}$ extension at $72^{\circ} \mathrm{C}$. At the end of each run, a melt curve was performed with readings from $65^{\circ} \mathrm{C}$ to $95^{\circ} \mathrm{C}$, at every $1{ }^{\circ} \mathrm{C}$, for $5 \mathrm{~s}$ to confirm that only the desired products were amplified. The negative controls NRT and NTC were included to validate the reactions. For every different gene analysed, NTC was incorporated to detect possible primer dimers formation and/or reagent contamination. Moreover, the NRT control enabled erroneous signals due to genomic DNA 
Table 2. MBEC value and recommended use concentration of each disinfectant (\%).

\begin{tabular}{llcc}
\hline Salmonella Enteritidis & BAC & HP & SH \\
\hline NCTC 13349 & 0.08 & 0.8 & 0.6 \\
350 & 0.16 & 0.8 & 0.12 \\
Recommended use concentration in food contact surfaces (FDA, 2019) & 0.02 & $0.02-0.03$ & 0.02 \\
\hline
\end{tabular}

contamination to be identified. All the Cq values of these controls were 10 or more cycles apart from the correspondent test sample, confirming the absence of contamination with genomic DNA or from qPCR reaction components, respectively.

\section{Gene expression analysis}

Data were analyzed using Bio-Rad CFX Manager ${ }^{\mathrm{TM}}$ version 1.6 (Bio-Rad Laboratories, Inc.) and a relative quantification method, Pfaffl analysis, which describes changes on the expression of target genes relative to a reference gene. Moreover, this method considers the reaction efficiencies of both target and reference genes (Pfaffl 2004). Each reaction was performed in triplicate and mean values of relative expression were analyzed for each target gene. Fold-change values $<1$ indicate a decrease in expression, $=1$ no change in expression and $>1$ indicates increase in expression levels relative to the control cells. Moreover, despite the existence of statistical differences $(* ; p<0.05)$, only differences above 2 -fold relative to 1 , which represents the control sample, were interpreted as being biologically significant $(t)$ (Kabir et al. 2015).

\section{Statistical analysis}

Data analysis was performed using GraphPad Prism ${ }^{\circledR}$ (GraphPad Software, Inc., San Diego, CA, USA). Biofilm formation results were compared using the Kruskal-Wallis test and Dunn's multiple comparisons test. qPCR results were compared using multiple $\mathrm{t}$ tests. All tests were performed with a confidence level of $95 \%$.

\section{Results and discussion}

\section{Susceptibility of S. Enteritidis biofilms to disinfectants}

The compounds chosen for this work represented different kinds of disinfectants commonly used in the food industry and also enabled the effect of different interaction mechanisms with bacterial cells to be investigated. Although MIC is a standard procedure to quantify the susceptibility of planktonic cells to these agents, MBEC testing should be considered when analyzing biofilms (Ceri et al. 1999; Allan et al.
2011). Hence, the biofilms' susceptibility to BAC, HP and $\mathrm{SH}$ were assessed, with MBEC values being presented in Table 2. These results show that, while $S$. Enteritidis biofilm cells from the reference strain (NCTC 13349) were more susceptible to benzalkonium chloride, biofilm cells from the food isolate (350) were more susceptible to sodium hypochlorite. Earlier studies focused on planktonic Salmonella enterica reported MIC values of $0.0015,0.01$ and $0.02 \%$ for BAC, HP and SH, respectively (DeQueiroz 2004; Mangalappalli-Illathu et al. 2008; Fazlara and Ekhtelat 2012). In the present work, the MBEC values obtained were much higher than these reported MIC values, which reflects the higher tolerance of biofilm cells compared to their planktonic counterparts and is in agreement with several pervious studies (Chylkova et al. 2017; González et al. 2018; Joseph et al. 2001; Scher et al. 2005). The lower susceptibility of these biofilms to oxidizing agents, compared to planktonic cells, may be related to the neutralization of these compounds by organic matter found in biofilms. Moreover, components of the biofilm matrix such as cellulose, which is one of the major components of Salmonella's biofilm matrix (Gerstel and Römling 2003), may also act as a diffusion barrier (Stewart et al. 2001). The production of cellulose allows the development of a biofilm matrix of tightly packed cells covered in a hydrophobic network (Peng 2016). A previous study has shown that cellulose-deficient mutants were more sensitive to chlorine treatments (Solano et al. 2002), proving the relevance of cellulose production in the survival of $S$. Enteritidis.

Furthermore, all the MBEC values determined were much higher than the recommended concentrations to be used for the disinfection of food contact surfaces (Table 2). These results suggest that, even when the recommended concentration of each disinfectant is applied (FDA, 2019), cells may persist in food processing areas. Moreover, through continuous exposure to sub-lethal concentrations of these agents, cells can develop resistance to them. There is evidence that some harmful bacteria found in food are becoming increasingly resistant to disinfectants, due to the increasing use of these compounds in the food industry and their frequent exposure to sub-lethal concentrations, which leads to bacterial adaptive resistance (Condell et al. 2012). So the use of these agents 
Table 3. Susceptibility of Salmonella Enteritidis NCTC 13349 and Salmonella Enteritidis 350 to antibiotics $\left(\mu \mathrm{g} \mathrm{ml} \mathrm{m}^{-1}\right.$ ).

\begin{tabular}{|c|c|c|c|c|c|c|c|}
\hline \multicolumn{3}{|c|}{ Antibiotics MIC breakpoints* } & AMP $S \leq 8 R>8$ & \multirow{2}{*}{$\begin{array}{c}\text { CIP } S \leq 0.06 \\
R>0.06 \\
1-2(\mathrm{R})\end{array}$} & \multirow{2}{*}{$\begin{array}{l}\text { CEF } S \leq 1 \mathrm{R}>2 \\
0.0625-0.125(\mathrm{~S})\end{array}$} & \multirow{2}{*}{$\begin{array}{c}\mathrm{CLO} S \leq 8 \mathrm{R}>8 \\
1-2(\mathrm{~S})\end{array}$} & \multirow{3}{*}{$\begin{array}{c}\text { TET } S \leq 4 \mathrm{R}>16 \\
0.5-1 \text { (S) } \\
0.5-1 \text { (S) }\end{array}$} \\
\hline NCTC 13349 & Planktonic & & $0.5-1(S)$ & & & & \\
\hline & Biofilm & Control & $0.5-1(S)$ & $8-16(\mathrm{R})$ & $0.125-0.25(\mathrm{~S})$ & $1-2(S)$ & \\
\hline & & BAC & $1-2(S)$ & $8-16(\mathrm{R})$ & $0.0625-0.125(S)$ & $2-4(S)$ & $0.5-1(\mathrm{~S})$ \\
\hline & & HP & $1-2(S)$ & $8-16(\mathrm{R})$ & $0.0625-0.125(S)$ & $1-2(S)$ & $0.5-1(\mathrm{~S})$ \\
\hline & & SH & $2-4(S)$ & $16-32(\mathrm{R})$ & $0.0625-0.125(\mathrm{~S})$ & $2-4(S)$ & $1-2(S)$ \\
\hline \multirow[t]{5}{*}{350} & Planktonic & & $1-2(S)$ & $8-16(\mathrm{R})$ & $0.0625-0.125(\mathrm{~S})$ & $4-8(S)$ & $0.5-1(\mathrm{~S})$ \\
\hline & Biofilm & Control & $1-2(S)$ & $8-16(\mathrm{R})$ & $0.125-0.25(\mathrm{~S})$ & $4-8(S)$ & $1-2(S)$ \\
\hline & & BAC & $1-2(S)$ & $8-16(\mathrm{R})$ & $0.0625-0.125(\mathrm{~S})$ & $2-4(S)$ & $0.5-1(\mathrm{~S})$ \\
\hline & & HP & $1-2(S)$ & $16-32(\mathrm{R})$ & $0.125-0.25(\mathrm{~S})$ & $2-4(S)$ & $0.5-1(\mathrm{~S})$ \\
\hline & & SH & $1-2(S)$ & $16-32(\mathrm{R})$ & $0.125-0.25(S)$ & $4-8(S)$ & $1-2(S)$ \\
\hline
\end{tabular}

The susceptibility test for ampicillin (AMP), ciprofloxacin (CIP), cefotaxime (CEF), chloramphenicol (CLO) and tetracycline (TET) was performed on planktonic cells, biofilms cells not exposed (control) and exposed to different disinfectants of S. Enteritidis NCTC 13349 and S. Enteritidis 350.

*Reference values by which bacteria can be assigned to the three clinical categories susceptible, standard dosing regimen (S), susceptible, increased exposure (I) and resistant (R) according to The European Committee on Antimicrobial Susceptibility Testing (EUCAST, 2019b).

should be revised, especially concerning disinfection of surfaces that are likely to be colonized by biofilms, in order not to trigger resistance caused by exposure to sub-lethal concentrations.

\section{Antibiotic susceptibility of S. Enteritidis cells derived from biofilms exposed to disinfectants}

Based on MBEC values, biofilms were periodically exposed to sub-lethal concentrations of each disinfectant, to study what may happen in the food industry when insufficient sanitation takes place. In order to simulate what can happen if cells from biofilms subjected to different disinfectants were released and cause human infection that requires antibiotic therapy, these cells were characterized with regard to their susceptibility to antibiotics commonly used to treat salmonellosis. Therefore, the analysis of antibiotic susceptibility can indicate whether the exposure to chemical agents affects the response of biofilm-derived cells to antibiotics and, eventually, if they would become resistant to them. Likewise, the susceptibility of planktonic cells not exposed to disinfectants was also determined to compare possible differences on antibiotic susceptibility between planktonic and biofilm-derived cells. MIC results are presented in Table 3, concerning S. Enteritidis NCTC 13349 and S. Enteritidis 350. In general, the results show that, before exposure to disinfectants, planktonic cells and biofilm-derived cells of both strains were equally susceptible to the antibiotics tested (Table 3). The only exception was for CIP and CEF, for the NCTC 13349 strain, and for CEF and TET, for the 350 strain, in which biofilmderived cells were less susceptible than planktonic cells. The lower susceptibility of cells within bacterial biofilms to antibiotics has previously been extensively reported (Papavasileiou et al. 2010). In this study, the MIC values of planktonic and biofilm-derived cells were quite similar, which may be related to the dissociation of the biofilms and subsequent analysis of the susceptibility of free-living cells, instead of cells within the cohesive bacterial community (Table 3 ). Since these cells were biofilm-derived cells and not biofilm cells, most biofilm features linked with a lower susceptibility towards antimicrobial agents were not present, and the results show that detached biofilm cells may not be as tolerant to antibiotics as when they are within a biofilm community.

A general overview of all MIC results (Tables 3) reveals that the concentrations for both strains were very similar, and did not reveal a pattern of true resistance after exposure to disinfectants (values were below the respective breakpoints (EUCAST - The European Committee on Antimicrobial Susceptibility Testing 2019b). The only exception was for CIP, to which a resistance pattern was observed for both planktonic and biofilm-derived cells, before and after disinfectant exposure. This observation is in agreement with previous reports, which showed that Salmonella enterica resistance to CIP has become a global concern (García-Fernández et al. 2015; Raveendran et al. 2008; Wang et al. 2017). The use of CIP as the antibiotic of choice in treating Salmonella enterica infections should thus be re-evaluated.

\section{Biofilm formation ability of S. Enteritidis cells derived from biofilms exposed to disinfectants}

Cells recovered from biofilms either exposed or not exposed to disinfectants were allowed to form biofilm for 3 days to determine whether exposure to chemical disinfectants altered their biofilm forming ability. Biofilm forming ability was evaluated by CV staining, and results are presented in Figure 1. For food isolate 350, no significant differences were observed. However, significant differences were observed for the 


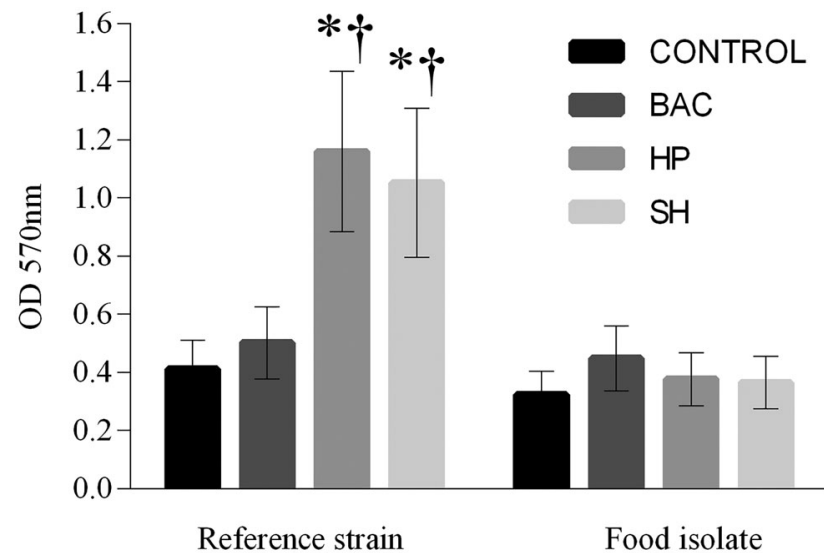

Figure 1. Biofilm formation by biofilm-derived cells following exposure to different disinfectants (BAC - benzalkonium chloride; HP - hydrogen peroxide; SH - sodium hypochlorite). Biofilm forming ability was evaluated by crystal violet staining. Bars represent average $\mathrm{CV} \mathrm{OD}_{570 \mathrm{~nm}}$ values and SDs from at least three independent assays. Symbols indicate statistically different values $(p \leq 0.05)$ within each strain comparing to the respective control $\left({ }^{*}\right)$ and between strains considering the same experimental condition $(\dagger)$.

reference strain NCTC 13349; biofilm-derived cells exposed to $\mathrm{HP}$ and $\mathrm{SH}$ showed a greater biofilm forming ability compared with the control (unexposed) cells, as well as with the food isolate 350 exposed to the same conditions $(p \leq 0.05)$. Although further studies are required to confirm this observation, oxidizing compounds may contribute to enhanced $S$. Enteritidis biofilm formation, which is in agreement with previous studies with different bacterial species and chemical compounds (Capita et al. 2014). This is a relevant subject since it indicates that the use of disinfecting agents at sub-lethal concentrations may increase the ability of bacteria to produce biofilms and potentiate their persistence in food processing areas.

\section{Effect of chemical disinfection on gene expression in S. Enteritidis biofilm-derived cells}

In order to determine if exposure to chemical disinfectants alters the expression of stress response and virulence genes in biofilm-derived cells, a qPCR analysis was performed. The gene expression analysis of invA, avrA, rpoS and $\operatorname{csg} D$ from biofilm-derived cells either exposed or not exposed to disinfectants is presented in Figure 2. Despite the existence of statistical differences $(* ; p<0.05)$, only differences above 2 -fold relative to 1 , which represents the control sample, were interpreted as being biologically significant $(t)$ (Kabir et al. 2015). It was not possible to analyze gene expression after exposure to $\mathrm{SH}$ because the amount of RNA extracted was too low to proceed with the gene expression assay. The low amount of RNA extracted was probably due to the low number of biofilm cells recovered, since there were only $5_{\log }$ CFU $\mathrm{ml}^{-1}$ in these samples (different studies and manufacturers' protocols recommend a concentration between $10^{7}-10^{9}$ CFU $\mathrm{ml}^{-1}$ for optimal RNA extraction) (Sirsat et al. 2011). Gene expression obtained after exposure to BAC and HP showed different expression patterns between the two strains, which may be related to intraspecies variability. Indeed, previous studies have also reported that the expression patterns of specifics morphotypes are serovar specific (e.g. Römling et al. 2003). For HP, despite it enhancing the biofilm forming ability of S. Enteritidis NCTC 13349 cells (Figure 1), no over-expression of $\operatorname{csg} D$ (which is a gene involved in the initial adhesion and biofilm formation (Latasa et al. 2005)), was detected (Figure 2(a)). Moreover, for the food isolate 350, exposure to $\mathrm{HP}$ resulted in a decrease in $\operatorname{csg} D$ expression compared to control biofilm-derived cells (Figure 2(b)). This apparent disparity between $\mathrm{CV}$ staining and qPCR analysis was also noticed for the effect of BAC on gene expression. Concerning the reference strain, S. Enteritidis NCTC 13349, although biofilm formation was not significantly altered after exposure to BAC (Figure 1), gene expression analysis revealed an up-regulation of $\operatorname{csgD}$ (Figure 2(a)). Nevertheless, a large standard deviation associated with the foldchange in expression was observed. Moreover, for the food isolate 350 a down-regulation of $\operatorname{csg} D$ was observed after exposure to BAC. To clarify the actual effect that exposure to $\mathrm{HP}$ and BAC has on gene expression and to correlate this with biofilm formation further analysis regarding Salmonella biofilm formation is required, including the assessment of other genes, which influence biofilm formation in this organism, such as $r b f A, o m p R, r c k, b c s A, m i s L$, yidR, spiA, sirA and $y c f R$ (Zhang et al. 2007; Kim and Wei 2009; Wang et al. 2010; Dong et al. 2011a; Dong et al. 2011b; Kroupitski et al. 2013; Liu et al. 2014). In addition to the analysis of gene expression patterns, there are several other factors that can be assessed to better understand the correlation between exposure to HP or BAC and Salmonella biofilm formation, such as biofilm-associated protein BapA, flagella, curli, cellulose and fatty acids (Römling et al. 1998; Solano et al. 2002; Barnhart and Chapman 2006, White et al. 2006), as well as plasmid-encoded fimbriae (Pef) and the long polar fimbriae (Lpf), which also contribute to the early steps in biofilm formation (Ledeboer et al. 2006). It is important to note that exposure to 

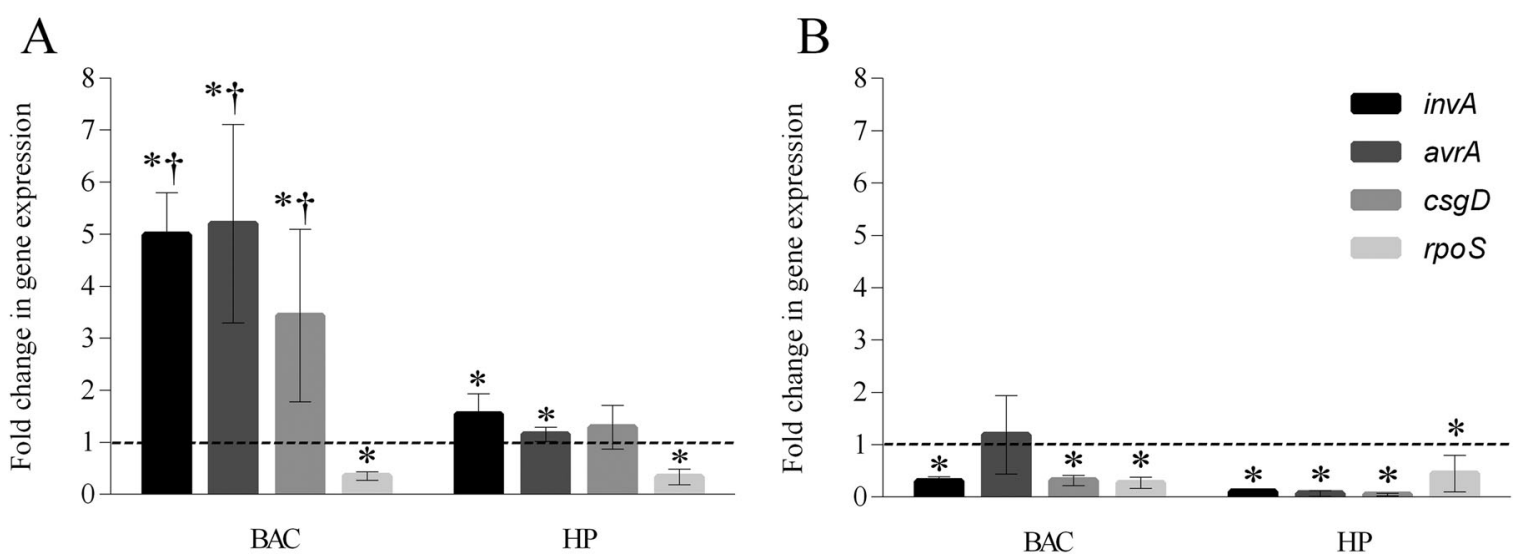

Figure 2. Gene expression analysis of biofilm-derived cells of Salmonella Enteritidis NCTC 13349 (A) and food isolate 350 (B). Results are shown as the fold-change in expression compared with that of control biofilm-derived cells (represented by a dotted line). Symbols indicate statistically significant differences $\left({ }^{*} ; p<0.05\right)$ and biologically significant differences ( $\dagger$; differences above 2 -fold) of gene expression analysis on biofilm-derived cells exposed to chemical disinfectants compared to the controls, from at least three independent assays.

BAC promoted the highest biologically significant $(\dagger)$ up-regulation of genes involved in cellular invasion (invA) and inflammatory response (avrA) (Figure $2(\mathrm{a})$ ), which is a concerning fact. Indeed, an overexpression of such genes may give the cells an increased ability to invade intestinal epithelial cell and inhibit inflammation, which could enhance the survival of this pathogen inside the host. The use of BAC should, then, be reconsidered since it may enhance the virulence and pathogenicity of $S$. Enteritidis biofilm-derived cells. However, similar invA and avrA up-regulation was not observed on $S$. Enteritidis food isolate 350, which once again shows intraspecies variability. For both strains, only the rpoS gene showed a decreased expression with statistical difference $(* ; p<0.05)$ compared to control biofilmderived cells after HP and BAC exposure (Figure 2). rpoS-encoded sigma factor $\left(\sigma^{\mathrm{S}}\right)$ is the master regulator of the general stress response in Gram-negative bacteria (Hengge-Aronis 1996). The general stress response is accompanied by a significantly reduced growth rate, which allows cells to survive long periods of starvation and different environmental stresses (Cohen et al. 2013). Moreover, this reduced growth rate is associated with the appearance of persister cells, which have been proposed to arise primarily in biofilms and in stationary-phase cultures (Lewis 2008) and are related to the reduced susceptibility of cells within biofilm to several antimicrobial compounds. However, in the current study the expression of rpoS was down-regulated under all conditions. This result suggests that exposure to BAC and HP did not reduce the growth rate of the cells and, consequently, did not promote the appearance of persister cells in $S$. Enteritidis biofilm-derived cells. This is a significant finding regarding the virulence of this foodborne pathogen, since persister cells can exhibit multidrug tolerance and be related to recalcitrance infections.

Although previous researchers have studied the gene expression profile of microorganisms that have survived disinfection (Wang et al. 2010), research on surviving biofilm cells is scarce (Rodrigues et al. 2011). However, in view of the current results, the up-regulation of virulence genes in cells within biofilms after exposure to disinfectants is a matter of concern.

BAC binds to phospholipids present in the cytoplasmic membrane of bacterial cells, causing a loss of structural integrity and impairing permeability (McBain et al. 2004). Although in this work exposure to BAC only slightly altered the susceptibility of the cells to the antibiotics tested (Table 3 ), the decreased susceptibility of $S$. Enteritidis NCTC 13349 to some antibiotics (AMP and CLO) after exposure to this disinfectant is in agreement with previous findings. For example, for planktonic cells, a high degree of crossresistance between BAC and several biocidal compounds, including CLO and $\beta$-lactam antibiotics, has previously been reported for Salmonella Virchow (Braoudaki and Hilton 2005). Despite the scarcity of the information available on biofilm cells, in the current study, the decreased susceptibility to AMP and CLO after BAC exposure of the NCTC 13349 strain can be related to the expression of efflux pumps systems. Indeed, a study by Mangalappalli-Illathu and Korber (2006) showed that adaptation of S. Enteritidis biofilms to BAC occurred with the up-regulation of key specific proteins involved in energy metabolism, protein biosynthesis, adaptation and detoxification, including proteins which might act as efflux pumps. 
Moreover, the AcrAB-TolC efflux system appears to direct efflux-mediated resistance to antibiotics such as quinolones, CLO and TET (Baucheron et al. 2004). Based on this information and the results obtained in the present study it is possible to infer that, as occurs in planktonic cells, an efflux pump system can be involved in the reduction of susceptibility to antibiotics of biofilm cells after exposure to BAC. Moreover, this compound had the highest influence on virulence gene expression (Figure 2(a)). The fact that cells exposed to disinfectants can over-express virulence genes is of concern, since these genes contribute to pathogenicity and may also be related to bacterial survival on exposure to adverse environmental conditions. Hence, the use of BAC should be reconsidered. $\mathrm{HP}$ is a compound that produces hydroxyl free radicals, which act as oxidants and react with lipids, proteins and DNA, increasing the permeability of cells (McDonnell and Russell 1999). As a chlorine compound, SH may damage the outer cell membrane, resulting in a loss of control of permeability, and also inhibit cellular enzymes or destroy DNA (Virto et al. 2005). Concerning biofilms, constituents of the extracellular matrix may play a key role in neutralizing antimicrobial agents, which consequently results in an increased resistance to them. In this study, these features were also corroborated by the high MBEC values (Table 2), as well as by the increased biofilm forming ability observed for $S$. Enteritidis NCTC 13349 after biofilm exposure to HP and SH (Figure 1). Although further studies are required to confirm this observation, the analysis of the effect of disinfection on biofilm formation showed that oxidizing compounds (such as SH and HP) may contribute to enhancing the biofilm forming ability of $S$. Enteritidis. This is a relevant subject, since the goal of disinfection is to eliminate pathogens, not to increase their persistence in food environments, as can be the case when enhancing biofilm formation.

This work shows that disinfecting agents commonly used in the food industry may represent a risk for public health, since they can increase virulence of foodborne pathogens. Although this has to be further confirmed with in vivo studies, these findings demonstrated that biofilm-derived cells of $S$. Enteritidis exposed to disinfectants can have an enhanced biofilm forming ability and/or an over-expression of virulence and stress response genes, which may lead to an increase in Salmonella pathogenicity in the case of an eventual infection. Finally, this work concludes that it is important to assess and understand the phenotypic characteristics of pathogenic biofilm-derived cells after exposure to chemical treatment since, besides enabling access to the mechanisms involved in biocidal resistance, this approach may allow the development of alternative treatments that avoid cross-resistance and/or induction of virulence and pathogenicity. Hence, development of new chemical-free control strategies involving enzyme solutions, bacteriophages, or microbial derived antimicrobial compounds continues to be an attractive research challenge.

\section{Conflicts of interest}

The authors declare that they have no conflict of interest.

\section{Funding}

This study was supported by the Portuguese Foundation for Science and Technology (FCT) under the scope of the strategic funding of unit UIDB/04469/2020 and BioTecNorte operation (NORTE-01-0145-FEDER-000004) funded by the European Regional Development Fund under the scope of Norte2020 - Programa Operacional Regional do Norte.

\section{ORCID}

Maria João Romeu (D) http://orcid.org/0000-0002-1094-5425

Joana Azeredo (D) http://orcid.org/0000-0002-5180-7133

\section{References}

Agarwal RK, Singh S, Bhilegaonkar KN, Singh VP. 2011. Optimization of microtitre plate assay for the testing of biofilm formation ability in different Salmonella serotypes. Int Food Res J. 18:1493-1498.

Allan ND, Omar A, Harding MW, Olson ME. 2011. A rapid, high-throughput method for culturing, characterizing and biocide efficacy testing of both planktonic cells and biofilms. In: Mendez-Vilasp A, editor. Science against microbial pathogens: communicating current research and technological advances. Microbiology Book Series: Number 3, Vol 2. Badajoz: Formatex; pp. 864-871.

Barnhart MM, Chapman MR. 2006. Curli biogenesis and function. Annu Rev Microbiol. 60:131-147. doi:10.1146/ annurev.micro.60.080805.142106

Baucheron S, Tyler S, Boyd D, Mulvey MR, Chaslus-Dancla E, Cloeckaert A. 2004. AcrAB-TolC directs efflux-mediated multidrug resistance in Salmonella enterica serovar Typhimurium DT104. Antimicrob Agents Chemother. 48:3729-3735. doi:10.1128/AAC.48.10.3729-3735.2004

Ben-Barak Z, Streckel W, Yaron S, Cohen S, Prager R, Tschäpe H. 2006. The expression of the virulence-associated effector protein gene avrA is dependent on a Salmonella enterica-specific regulatory function. Int J Med Microbiol. 296:25-38. doi:10.1016/j.ijmm.2005.08. 004

Braoudaki M, Hilton AC. 2005. Mechanisms of resistance in Salmonella enterica adapted to erythromycin, 
benzalkonium chloride and triclosan. Int J Antimicrob Agents. 25:31-37. doi:10.1016/j.ijantimicag.2004.07.016

Capita R, Riesco-Peláez F, Alonso-Hernando A, AlonsoCalleja C. 2014. Exposure of Escherichia coli ATCC 12806 to sublethal concentrations of food-grade biocides influences its ability to form biofilm, resistance to antimicrobials, and ultrastructure. Appl Environ Microbiol. 80:1268-1280. doi:10.1128/AEM.02283-13

Carrasco E, Morales-Rueda A, García-Gimeno RM. 2012. Cross-contamination and recontamination by Salmonella in foods: a review. Food Res Int. 45:545-556. doi:10. 1016/j.foodres.2011.11.004

Carson L, Chau P K W, Earle M J, Gilea M A, Gilmore B F, Gorman S P, Mccann M T, Seddon K R. 2009. Antibiofilm activities of 1-alkyl-3-methylimidazolium chloride ionic liquids. Green Chem. 11:492-497. doi: 10. 1039/B821842K

Ceri H, Olson ME, Stremick C, Read RR, Morck D, Buret A. 1999. The Calgary Biofilm Device: new technology for rapid determination of antibiotic susceptibilities of bacterial biofilms. J Clin Microbiol. 37:1771-1776. doi:10. 1128/JCM.37.6.1771-1776.1999

Chylkova T, Cadena M, Ferreiro A, Pitesky M. 2017. Susceptibility of Salmonella biofilm and planktonic bacteria to common disinfectant agents used in poultry processing. J. Food Prot. 80:1072-1079. doi:10.4315/ 0362-028X.JFP-16-393

Cohen NR, Lobritz MA, Collins JJ. 2013. Microbial persistence and the road to drug resistance. Cell Host Microbe. 13:632-642. doi:10.1016/j.chom.2013.05.009

Condell O, Iversen C, Cooney S, Power KA, Walsh C, Burgess C, Fanning S. 2012. Efficacy of biocides used in the modern food industry to control Salmonella enterica, and links between biocide tolerance and resistance to clinically relevant antimicrobial compounds. Appl Environ Microbiol. 78:3087-3097. doi:10.1128/AEM. 07534-11

Corcoran M, Morris D, De Lappe N, O'Connor J, Lalor P, Dockery P, Cormican M. 2014. Commonly used disinfectants fail to eradicate Salmonella enterica biofilms from food contact surface materials. Appl Environ Microbiol. 80:1507-1514. doi:10.1128/AEM.03109-13

DeQueiroz G. 2004. A new broad spectrum disinfectant suitable for the food industry [Doctoral dissertation]. Philosophy in Food Science, Louisiana State University and Agricultural and Mechanical College, Baton Rouge, LO.

Dong H, Peng D, Jiao X, Zhang X, Chen S, Lu Y, Geng S, Liu X. 2011. Construction and characterization of an $o m p R$ gene deletion mutant from Salmonella enteritidis. Wei Sheng Wu Xue Bao. 51:1256-1262.

Dong H, Peng D, Jiao X, Zhang X, Geng S, Liu X. 2011. Roles of the spiA gene from Salmonella enteritidis in biofilm formation and virulence. Microbiology. 157:1798-1805. doi:10.1099/mic.0.046185-0

European Food Safety Authority and European Centre for Disease Prevention and Control (EFSA and ECDC). 2018. The European Union summary report on trends and sources of zoonoses, zoonotic agents and food-borne outbreaks in 2017. https://efsa.onlinelibrary.wiley.com/ doi/epdf/10.2903/j.efsa.2018.5500.
Fazlara A, Ekhtelat M. 2012. The disinfectant effects of benzalkonium chloride on some important foodborne pathogens. Am J Agric Environ Sci. 12:23-29.

Food and Drug Administration (FDA). 2019. CFR - Code of federal regulations Title 21, Volume 3, 21CFR178.1010, Part 178 - Indirect food additives: adjuvants, production aids, and sanitizers. Subpart B Substances utilized to control the growth of microorganisms. Sec. 178.1010 Sanitizing solutions. Revised as of April 1, 2019. https://www.accessdata.fda.gov/scripts/ cdrh/cfdocs/cfcfr/cfrsearch.cfm?fr=178.1010.

Galá n JE, Ginocchio C, Costeas P. 1992. Molecular and functional characterization of the Salmonella invasion gene invA: homology of InvA to members of a new protein family. J Bacteriol. 174:4338-4349. doi:10.1128/JB. 174.13.4338-4349.1992

García-Ferná ndez A, Gallina S, Owczarek S, Dionisi AM, Benedetti I, Decastelli L, Luzzi I. 2015. Emergence of ciprofloxacin-resistant Salmonella enterica serovar Typhi in Italy. Cloeckaert A, editor. PLoS One. 10:e0132065. doi:10.1371/journal.pone.0132065

Gerstel U, Römling U. 2003. The $\operatorname{csgD}$ promoter, a control unit for biofilm formation in Salmonella typhimurium. Res Microbiol. 154:659-667. doi:10.1016/j.resmic.2003.08. 005

Giaouris E, Chorianopoulos N, Skandamis P, Nychas G. 2012. Attachment and biofilm formation by Salmonella in food processing environments. In: Mahmoud BSM, editor. Salmonella: a danger foodborne pathog. New York: InTEch, Open Access Publisher; p. 157-180.

Giaouris E, Samoilis G, Chorianopoulos N, Ercolini D, Nychas GJ. 2013. Differential protein expression patterns between planktonic and biofilm cells of Salmonella enterica serovar Enteritidis PT4 on stainless steel surface. Int J Food Microbiol. 162:105-113. doi:10.1016/j.ijfoodmicro. 2012.12.023

González JF, Alberts H, Lee J, Doolittle L, Gunn JS. 2018. Biofilm formation protects Salmonella from the antibiotic ciprofloxacin in vitro and in vivo in the mouse model of chronic carriage. Sci Rep. 8:222. doi:10.1038/s41598-01718516-2

Hengge-Aronis R. 1996. Back to log phase: sigma S as a global regulator in the osmotic control of gene expression in Escherichia coli. Mol Microbiol. 21:887-893. doi: 10.1046/j.1365-2958.1996.511405.x

Jorgensen JH, Ferraro MJ. 2009. Antimicrobial susceptibility testing: a review of general principles and contemporary practices. Clin Infect Dis. 49:1749-1755. doi:10.1086/ 647952

Joseph B, Ott SK, Karunasagar I, Karunasagar I. 2001. Biofilm formation by Salmonella spp. on food contact surfaces and their sensitivity to sanitizers. Int J Food Microbiol. 64:367-372. doi:10.1016/S0168-1605(00)00466-9

Kabir FLM, DeInnocentes P, Bird RC. 2015. Altered microRNA expression profiles and regulation of INK4A/ CDKN2A tumor suppressor genes in canine breast cancer models. J Cell Biochem. 116:2956-2969. doi:10.1002/ jcb. 25243

Kim S-H, Wei C-I. 2009. Molecular characterization of biofilm formation and attachment of Salmonella enterica serovar Typhimurium DT104 on food contact surfaces. J Food Prot. 72:1841-1847. doi:10.4315/0362-028X-72.9.1841 
Kit WH, M, Mohtar DA, Hui LM, Sattar ZM, Abdul Halim AN, Muhamad NS, S, Sulukan F, Abdul Majid AM. 2011. Salmonellosis: the diseases, treatment, prevention and drug resistance. WebmedCentral Bacteriol. 2:1-13.

Kroupitski Y, Brandl MT, Pinto R, Belausov E, Tamir-Ariel D, Burdman S, Sela (Saldinger) S. 2013. Identification of Salmonella enterica genes with a role in persistence on lettuce leaves during cold storage by recombinase-based in vivo expression technology. Phytopathology. 103: 362-372. doi:10.1094/PHYTO-10-12-0254-FI

Latasa C, Roux A, Toledo-Arana A, Ghigo JM, Gamazo C, Penadés JR, Lasa I. 2005. BapA, a large secreted protein required for biofilm formation and host colonization of Salmonella enterica serovar Enteritidis. Mol Microbiol. 58:1322-1339. doi:10.1111/j.1365-2958.2005.04907.x

Ledeboer NA, Frye JG, McClelland M, Jones BD. 2006. Salmonella enterica serovar Typhimurium requires the Lpf, Pef, and Tafi fimbriae for biofilm formation on HEp-2 tissue culture cells and chicken intestinal epithelium. Infect Immun. 74:3156-3169. doi:10.1128/IAI. 01428-05

Lewis K. 2008. Multidrug tolerance of biofilms and persister cells. In Romeo $\mathrm{T}$, editor. Bacterial biofilms. Berlin, Germany: Springer-Verlag; p. 107-131.

Liu Z, Que F, Liao L, Zhou M, You L, Zhao Q, Li Y, Niu $\mathrm{H}, \mathrm{Wu} \mathrm{S}$, Huang R. 2014. Study on the promotion of bacterial biofilm formation by a Salmonella conjugative plasmid and the underlying mechanism. Plos One. 9:e109808. doi:10.1371/journal.pone.0109808

Mangalappalli-Illathu AK, Korber DR. 2006. Adaptive resistance and differential protein expression of Salmonella enterica serovar Enteritidis biofilms exposed to benzalkonium chloride. Antimicrob Agents Chemother. 50:3588-3596. doi:10.1128/AAC.00573-06

Mangalappalli-Illathu AK, Vidović S, Korber DR. 2008. Differential adaptive response and survival of Salmonella enterica serovar enteritidis planktonic and biofilm cells exposed to benzalkonium chloride. Antimicrob Agents Chemother. 52:3669-3680. doi:10.1128/AAC.00073-08

McBain AJ, Ledder RG, Moore LE, Carl E, Gilbert P, Catrenich CE. 2004. Effects of quaternary-ammoniumbased formulations on bacterial community dynamics and antimicrobial susceptibility effects of quaternaryammonium-based formulations on bacterial community dynamics and antimicrobial susceptibility. Appl Environ Microbiol. 70:3449-3456. doi:10.1128/AEM.70.6.34493456.2004

McDonnell G, Russell AD. 1999. Antiseptics and disinfectants: activity, action, and resistance. Clin Microbiol Rev. 12:147-179. doi:10.1128/CMR.12.1.147

Moore G, Blair IS, McDowell DA. 2007. Recovery and transfer of Salmonella typhimurium from four different domestic food contact surfaces. J Food Prot. 70: 2273-2280. doi:10.4315/0362-028X-70.10.2273

O’Neal CR, Gabriel WM, Turk AK, Libby SJ, Fang FC, Spector MP. 1994. RpoS is necessary for both the positive and negative regulation of starvation aurvival genes during phosphate, carbon, and nitrogen starvation in Salmonella typhimurium. J Bacteriol. 176:4610-4616. doi: 10.1128/JB.176.15.4610-4616.1994

Papavasileiou K, Papavasileiou E, Tseleni-Kotsovili A, Bersimis S, Nicolaou C, Ioannidis A, Chatzipanagiotou S.
2010. Comparative antimicrobial susceptibility of biofilm versus planktonic forms of Salmonella enterica strains isolated from children with gastroenteritis. Eur J Clin Microbiol Infect Dis. 29:1401-1405. doi:10.1007/s10096010-1015-y

Peng D, 2016. Biofilm formation of Salmonella. In. Dhanasekaran D, editor. Microbial biofilms: importance and applications. New York: InTEch, Open Access Publisher; p. 231-249.

Pfaffl MW. 2004. Quantification strategies in real-time PCR. In: Bustin SA, editor. Real-time PCR Encycl A-Z Quant PCR. La Jolla, CA: International University Line; p. $87-112$.

Raveendran R, Wattal C, Sharma A, Oberoi JK, Prasad JK, Datta S. 2008. High level ciprofloxacin resistance in Salmonella enterica isolated from blood. Indian J Med Microbiol. 26:50-53.

Rodrigues D, Cerca N, Teixeira P, Oliveira R, Ceri H, Azeredo J. 2011. Listeria monocytogenes and Salmonella enterica enteritidis biofilms susceptibility to different disinfectants and stress-response and virulence gene expression of surviving cells. Microb Drug Resist. 17:181-189. doi:10.1089/mdr.2010.0183

Römling U, Bian Z, Hammar M, Sierralta W D, Normark S. 1998. Curli fibers are highly conserved between Salmonella typhimurium and Escherichia coli with respect to operon structure and regulation. J Bacteriol. 180: 722-731. doi:10.1128/JB.180.3.722-731.1998

Römling U, Bokranz W, Rabsch W, Zogaj X, Nimtz M, Tschä pe H. 2003. Occurrence and regulation of the multicellular morphotype in Salmonella serovars important in human disease. Int J Med Microbiol. 293:273-285. doi:10.1078/1438-4221-00268

Rozen S, Skaletsky H. 2000. Primer3 on the WWW for general users and for biologist programmers. Methods Mol Biol. 132:365-386.

Scher K, Romling U, Yaron S. 2005. Effect of heat, acidification, and chlorination on Salmonella enterica serovar Typhimurium cells in a biofilm formed at the air-liquid interface. Appl Environ Microbiol. 71:1163-1168. doi:10. 1128/AEM.71.3.1163-1168.2005

Sirsat SA, Muthaiyan A, Ricke SC. 2011. Optimization of the RNA extraction method for transcriptome studies of Salmonella inoculated on commercial raw chicken breast samples. BMC Res Notes. 4:60. doi:10.1186/1756-0500-460

Solano C, García B, Valle J, Berasain C, Ghigo J-M, Gamazo C, Lasa I. 2002. Genetic analysis of Salmonella enteritidis biofilm formation: critical role of cellulose. Mol Microbiol. 43:793-808. doi:10.1046/j.1365-2958.2002. 02802.x

Steenackers H, Hermans K, Vanderleyden J, De Keersmaecker S. 2012. Salmonella biofilms: an overview on occurrence, structure, regulation and eradication. Food Res Int. 45:502-531. doi:10.1016/j.foodres.2011.01. 038

Stewart PS, Rayner J, Roe F, Rees WM. 2001. Biofilm penetration and disinfection efficacy of alkaline hypochlorite and chlorosulfamates. J Appl Microbiol. 91:525-532. doi: 10.1046/j.1365-2672.2001.01413.x 
The European Committee on Antimicrobial Susceptibility Testing (EUCAST). 2019a. EUCAST reading guide for broth microdilution. Version 9.0.

The European Committee on Antimicrobial Susceptibility Testing (EUCAST). 2019b. Breakpoint tables for interpretation of MICs and zone diameters. Version 9.0.

Virto R, Mañas P, Álvarez I, Condon S, Raso J. 2005. Membrane damage and microbial inactivation by chlorine in the absence and presence of a chlorine-demanding substrate membrane damage and microbial inactivation by chlorine in the absence and presence of a chlorinedemanding substrate. Appl Environ Microbiol. 71: 5022-5028. doi:10.1128/AEM.71.9.5022-5028.2005

Wang J, Li Y, Xu X, Liang B, Wu F, Yang X, Ma Q, Yang C, $\mathrm{Hu} \mathrm{X}$, Liu H, et al. 2017. Antimicrobial resistance of
Salmonella enterica serovar Typhimurium in Shanghai, China. Front Microbiol. 8:510

Wang S, Phillippy AM, Deng K, Rui X, Li Z, Tortorello ML, Zhang W. 2010. Transcriptomic responses of Salmonella enterica serovars Enteritidis and Typhimurium to chlorine-based oxidative stress. Appl Environ Microbiol. 76: 5013-5024. doi:10.1128/AEM.00823-10

White AP, Gibson DL, Kim W, Kay WW, Surette MG, Acteriol JB. 2006. Thin aggregative fimbriae and cellulose enhance long-term survival and persistence of Salmonella. J Bacteriol. 188:3219-3227. doi:10.1128/JB. 188.9.3219-3227.2006

Zhang X-S, García-Contreras R, Wood TK. 2007. YcfR (BhsA) influences Escherichia coli biofilm formation through stress response and surface hydrophobicity. J Bacteriol. 189:3051-3062. doi:10.1128/JB.01832-06 